\title{
Monitoring marine plankton ecosystems. II: Long-term changes in North Sea calanoid copepods in relation to hydro-climatic variability
}

\author{
Grégory Beaugrand $^{1, *}$, Frédéric Ibanez ${ }^{2}$ \\ ${ }^{1}$ CNRS, UMR 8013 ELICO, Université de Lille 1, BP 80, 28 avenue Foch, 62930 Wimereux, France \\ ${ }^{2}$ Observatoire océanologique, Laboratoire d'océanologie de Villefranche-sur-Mer, BP 28, \\ 06230 Villefranche-sur-Mer, France
}

\begin{abstract}
Recently, a framework has been proposed to monitor plankton ecosystems in the North Atlantic and adjacent seas using calanoid copepod species. In this study, we use this framework to investigate, at the community structure (calanoid copepod) level, the long-term changes in plankton ecosystems related to hydro-climatic variability in the North Sea during the period 1958-1999. A chronology of ecological events that occurred in the North Sea is outlined. In addition to the longterm and year-to-year variability, this study reveals that North Sea plankton ecosystems had 2 dynamic regimes during the period 1958-1999: a cold-biological (1962-1982) and a warm-biological dynamic regime (1984-1999). The impact of the regime shift on the community structure of calanoid copepods and total diversity (as mean number of calanoid copepod species per continuous plankton recorder sample) is detectable in the stratified regions of the North Sea after ca. 1983. This study reveals that the regime shift resulted from the conjunction of both local and regional hydro-climatic forcing and a change in the location of an oceanic biogeographical boundary in the north-east Atlantic Ocean. Results indicate a strong dependence of ecological processes in the North Sea to both hydro-climatic and biological variability in the north-east Atlantic Ocean. If the current climate warming persists, results suggest that this may continue to alter the structure of North Sea ecosystems and lead to other regime shifts, thus making it very challenging to predict future responses of North Sea pelagic ecosystems to climate change.
\end{abstract}

KEY WORDS: Plankton monitoring $\cdot$ Calanoid copepods $\cdot$ Hydro-climatic forcing $\cdot$ Continuous plankton recorder survey

\section{INTRODUCTION}

Plankton play an important role in the functioning of marine ecosystems and in biogeochemical cycles (Roemmich \& McGowan 1995). Interannual changes of their species assemblages often reflect an integrated response of the ecosystem to hydro-climatic forcing. Many authors have suggested that plankton may be used as an indicator of climate change (Reid \& Beaugrand 2002), and a plethora of studies using the dataset of the Continuous Plankton Recorder (CPR) survey have documented relationships between plankton and hydro-climatic variability in the North Atlantic Ocean (e.g. Colebrook 1991, Fromentin \& Planque 1996, Reid et al. 1998, Beaugrand et al. 2000). For example, decreasing trends observed in the abundance of many zooplanktonic species until about 1980 were attributed to the effects of sea level pressure anomalies on the intensification of northerly winds and storminess, which may delay or decrease the intensity of the spring bloom and as a consequence reduce the carrying capacity for zooplankton (Dickson et al. 1988a). An alternative hypothesis was also proposed by Colebrook (1991), who attributed this long-term decrease 
Table 1. List of species assemblage indicators and their ecological preferences. More information about the biological composition of each species assemblage indicator can be found in Beaugrand et al. (2002a)

\begin{tabular}{|c|c|c|}
\hline $\begin{array}{l}\text { Species assem- } \\
\text { blage no. }\end{array}$ & Species assemblage indicators & Ecological preferences \\
\hline A1 & $\begin{array}{l}\text { Warm-temperate pseudo-oceanic } \\
\text { species }\end{array}$ & $\begin{array}{l}\text { Warm water south of about } 50^{\circ} \mathrm{N} \text { along the European } \\
\text { shelf edge }\end{array}$ \\
\hline A2 & $\begin{array}{l}\text { Temperate pseudo-oceanic } \\
\text { species }\end{array}$ & $\begin{array}{l}\text { Oceanic and neritic water, especially along shelf edges north } \\
\text { to about } 55^{\circ} \mathrm{N}\end{array}$ \\
\hline A3 & Coastal species & Shallow and coastal habitat \\
\hline A 4 & Shelf-sea species & Neritic distribution \\
\hline A5 & Cold-temperate species & $\begin{array}{l}\text { Mixed water usually found at the boundary between warm } \\
\text { and subarctic water (e.g. Oceanic Polar Front) }\end{array}$ \\
\hline A6 & Subarctic species & Subarctic water \\
\hline A7 & Arctic species & Arctic water \\
\hline
\end{tabular}

in plankton abundance to the reduction of westerly winds, which may decrease the success of overwintering of some key species.

More recently, Fromentin \& Planque (1996) discovered that year-to-year changes in the North Atlantic Oscillation (NAO) and the abundance of the subarctic species Calanus finmarchicus around the British Isles were negatively correlated. They also showed that the warmer-water pseudo-oceanic (i.e. 'shelf break') species $C$. helgolandicus was positively related to the NAO, although the relationship was weaker and with a 1 yr lag. Many hypotheses were proposed to explain the link between the NAO and these species: wind-induced turbulence and prey-predator interaction, the influence of temperature on competition between both species, bottom-up control, changes in biogeographical boundaries between both species, the volume of Norwegian Sea Deep Water in which C. finmarchicus is known to overwinter and the flow of the European shelf edge current (Fromentin \& Planque 1996, Planque \& Reid 1998, Stephens et al. 1998, Reid \& Planque 2000).

In addition to the relationships detected between climatic features and plankton, Reid et al. (2001a,b) have recently documented one of the largest changes in North Sea plankton, referring to it as a regime shift, which took place ca. 1988. The term regime shift has usually been used to describe large decadal-scale switches in the abundance and composition of plankton and fish (Reid et al. 2001a). Many changes in the biological composition of marine ecosystems in the North Sea were also observed at the end of the 1980s (Lindley et al. 1990, 1993, Greve 1994). For example, the doliolid Doliolum nationalis, the dinoflagellate Ceratium extensum and the siphonophore Muggiaea atlantica, which are usually found in oceanic water, were detected in the central part of the North Sea in 1989 (Lindley et al. 1990, Greve 1994). Phytoplankton colour, a CPR-derived visual index of chlorophyll, also showed a stepwise increase in intensity and seasonal extent after 1987 (Reid et al. 1998). This cascade of biological events was accompanied by an increase in catches of horse mackerel (Reid et al. 2001b) and changes in benthic community structure in the southern North Sea (Kroncke et al. 1998, Warwick et al. 2002). Physico-chemical changes such as an increase in sea surface temperature (SST) and changes in the concentration of certain nutrients and oxygen were also detected in the Skagerrak at about the same time (Dahl \& Danielssen 1992).

In many studies (e.g. Fromentin \& Planque 1996, Reid et al. 2001a, Taylor 2002, Beaugrand \& Reid 2003), the link between climate and plankton was not investigated at the community level but by focussing on individual species. Such studies have limited potential for inferring changes to the (plankton) ecosystem level. Beaugrand (2004) has recently proposed a procedure for monitoring the dynamic regime of plankton ecosystems based on all calanoid copepods. This procedure uses the calanoid copepod species assemblage indicators proposed by Beaugrand et al. $(2002 \mathrm{a}, \mathrm{b}, \mathrm{c})$ to examine long-term changes in the dynamic regime of plankton ecosystems. In this study, we used this ecosystem approach to examine changes in plankton ecosystems of the North Sea and to investigate potential links with hydro-climatic forcing. A chronology of ecological events that occurred in the North Sea during the period 1958-1999 is outlined and new evidence and hypotheses about the regime shift in the North Sea are presented.

\section{MATERIALS AND METHODS}

Biological data. Biological data used in this study have been collected by the CPR survey, an upper layer plankton monitoring programme that has regularly 
collected more than 400 taxa in the North Atlantic and North Sea since 1946 (Warner \& Hays 1994). Sampling is carried out by a high-speed plankton recorder (ca. $20 \mathrm{~km} \mathrm{~h}^{-1}$ ) that is voluntarily towed behind merchant ships at a depth of approximately 6 to $7 \mathrm{~m}$. Despite the near-surface sampling, studies showed that this machine gives a satisfactory picture of the epipelagic zone (Lindley \& Williams 1980, Williams \& Lindley 1980, Batten et al. 1999). Water enters the CPR through a small aperture at the front of the instrument and travels down a tunnel, where it passes through a silk filtering mesh of $270 \mu \mathrm{m}$ before exiting at the back of the CPR. On return to the laboratory, the silk roll is unwound and cut into sections corresponding to 10 nautical miles and approximately $3 \mathrm{~m}^{3}$ of filtered seawater (Warner \& Hays 1994). More details on methods and contents of this dataset are described in Warner \& Hays (1994).

Calanoid copepods were used because this group (1) represents one of the best taxa sampled by the CPR, (2) is often the most abundant zooplankton, and (3) is a key link between phytoplankton and fish. The CIMOTS (Copepod Indicator Monitoring Toolbox System; Beaugrand 2004) procedure was used to calculate time series of both the mean total number of calanoid copepod species per CPR sample (as a measure of total diversity) and the mean number of species that belong to each of the species assemblages defined by Beaugrand et al. (2002a). Both calanoid copepod species assemblages and calanoid copepod total diversity are also referred to as plankton indicators hereafter in the text. The CIMOTS procedure randomly selects a constant number of samples for each time period to calculate the value of the plankton indicators. Table 1 describes the ecological preference of each species assemblage; the biological composition of each species assemblage can be found in Beaugrand (2004, his Table 1).

The species assemblage indicators (and total diversity as the mean number of calanoid copepod species per CPR sample) were calculated in 4 regions of the North Sea (Table 2). The 4 areas (Fig. 1) were defined on the basis of the work done by Beaugrand et al. (2001). Three of these 4 areas (Areas 1, 2 and 3 in Fig. 1) corresponded to the 3 major ecological subdivisions put forward by findings based on data on phytoplankton (Reid et al. 1990), zooplankton (Fransz et al. 1991) and fish (Daan et al. 1990) distributions. The examination of seasonal variability in calanoid copepod total diversity (Beaugrand et al. 2001) identified a fourth area, the north-western part of the North Sea, which shared common patterns in calanoid copepod total diversity with the northern part of the North Atlantic Drift Province (Area 4 in Fig. 1; Beaugrand et al. 2001). As shown in Table 2,
Area 4 does not have exactly the same calanoid copepod composition. A total of 23 plankton time series were constructed for the period 1958-1999 in the 4 regions of the North Sea (Table 2). The species assemblages selected in each region of the North Sea were those present for more than 20 yr during the period 1958-1999.

Table 2. List of both biological and hydro-climatic variables (and their abbreviation) used in this study. A pseudo-oceanic species assemblage is composed of species present in both neritic and oceanic water but occurring preferentially above the continental shelf break (Beaugrand et al. 2002a). Area 1: southern North Sea (s); Area 2: central North Sea (c); Area 3: north-east North Sea (ne); Area 4: north-west North Sea (nw)

\begin{tabular}{|c|c|}
\hline Plankton indicator & Abbreviation \\
\hline \multicolumn{2}{|l|}{ Area 4} \\
\hline $\begin{array}{l}\text { Warm-temperate pseudo-oceanic } \\
\text { oceanic species (A1) }\end{array}$ & A1nw \\
\hline Temperate pseudo-oceanic species (A2) & A2nw \\
\hline Shelf-sea species (A4) & A4nw \\
\hline Cold-temperate species (A5) & A5nw \\
\hline Subarctic species (A6) & A6nw \\
\hline Total calanoid copepod diversity $(D)$ & Dnw \\
\hline \multicolumn{2}{|l|}{ Area 3} \\
\hline Temperate pseudo-oceanic species (A2) & A2ne \\
\hline Shelf-sea species (A4) & A4ne \\
\hline Cold-temperate species (A5) & A5ne \\
\hline Subarctic species (A6) & A6ne \\
\hline Arctic species (A7) & A7ne \\
\hline Total calanoid copepod diversity $(D)$ & Dne \\
\hline \multicolumn{2}{|l|}{ Area 2} \\
\hline Temperate pseudo-oceanic species (A2) & $\mathrm{A} 2 \mathrm{C}$ \\
\hline Shelf-sea species (A4) & $\mathrm{A} 4 \mathrm{C}$ \\
\hline Cold-temperate species (A5) & A5c \\
\hline Subarctic species (A6) & $\mathrm{A} 6 \mathrm{c}$ \\
\hline Total calanoid copepod diversity $(D)$ & Dc \\
\hline \multicolumn{2}{|l|}{ Area 1} \\
\hline Temperate pseudo-oceanic species (A2) & A2s \\
\hline Coastal species (A3) & A3s \\
\hline Shelf-sea species (A4) & $\mathrm{A} 4 \mathrm{~s}$ \\
\hline Cold-temperate species (A5) & A $5 \mathrm{~s}$ \\
\hline Subarctic species (A6) & A6s \\
\hline Total calanoid copepod diversity $(D)$ & Ds \\
\hline \multicolumn{2}{|l|}{ Hydro-climatic variables } \\
\hline Sea surface temperature & SST \\
\hline Wind intensity & WI \\
\hline U-Wind & WU \\
\hline V-Wind & WV \\
\hline Gulf Stream North Wall index & GSNW \\
\hline $\begin{array}{l}\text { Hurrell's (1995) winter North Atlantic } \\
\text { Oscillation index }\end{array}$ & NAO \\
\hline Northern Hemisphere Temperature anomalies & NHT \\
\hline Beaugrand et al.'s (2002c) north-east & PCT \\
\hline Atlantic sea surface temperature index & \\
\hline
\end{tabular}




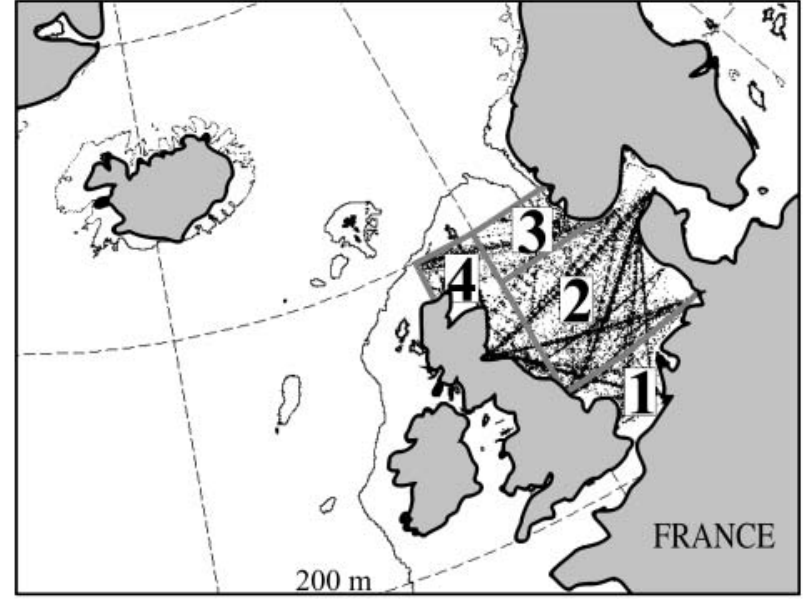

Fig. 1. The 4 areas selected for the estimation of total calanoid copepod total diversity and the number of species for each representative species assemblage indicator. Area 1: south North Sea $\left(51^{\circ} \mathrm{N}, 54^{\circ} \mathrm{N}, 0^{\circ} \mathrm{W}, 10^{\circ} \mathrm{E}\right.$; a total of 7579 samples). Five CPR samples per 2 mo interval from 1958-1999 were used to build time series of the species assemblages 2 to 6 (see Tables 1 \& 2). Area 2: central North Sea $\left(54^{\circ} \mathrm{N}, 58^{\circ} \mathrm{N}, 0^{\circ} \mathrm{W}\right.$, $10^{\circ} \mathrm{E}$; a total of 22417 samples). Thirty CPR samples per 2 mo interval from 1958-1999 were used to build time series of the species assemblages 2 and 4 to 6 . Area 3: north-east North Sea $\left(58^{\circ} \mathrm{N}, 60^{\circ} \mathrm{N}, 0^{\circ} \mathrm{W}, 10^{\circ} \mathrm{E}\right.$; a total of 3982 samples). Six CPR samples per 2 mo interval from 1958-1999 were used to build time series of the species assemblages 2 and 4 to 7 . Area 4: north-west North Sea $\left(54^{\circ} \mathrm{N}, 60^{\circ} \mathrm{N}, 4^{\circ} \mathrm{W}, 0^{\circ} \mathrm{E}\right.$; a total of 12,111 samples). Twenty-five CPR samples per 2 mo interval from 1958-1999 were used to build time series of the species assemblages 1,2 and 4 to 6 . Boundary between areas are indicated by thick grey lines

Local hydro-climatic variables. ICES SSTs in the North Sea were provided by Keith Brander (ICES, Copenhagen). A programme was written to calculate the annual mean of this variable for the whole North Sea.

COADS (Comprehensive Ocean-Atmosphere Data Set) 1-degree enhanced data were provided by the NOAA-CIRES Climate Diagnostics Center (Boulder, Colorado, USA) (Woodruff et al. 1987). This dataset based on in situ historical marine observations represents one of the most extensive collection of surface marine data available for most regions of the world. Data are organised in a $1^{\circ}$ longitude and $1^{\circ}$ latitude box available for every month of the period 1960-1997. Scalar wind (intensity of wind, in $\mathrm{m} \mathrm{s}^{-1}$ ), U-wind intensity (mean intensity of the south to north component of wind, in $\mathrm{m} \mathrm{s}^{-1}$ ) and $\mathrm{V}$-wind intensity (mean intensity of the west to east component of wind, in $\mathrm{m} \mathrm{s}^{-1}$ ) were used in this study. An annual mean was calculated for every COADS variable for the whole North Sea (Table 2).

We chose to calculate the average value for the whole North Sea for each climatological parameter because a cluster analysis showed that the values of each parameter for the 4 areas selected in the North Sea were very similar.

Large-scale hydro-climatic variables. Four largescale hydro-climatic indices were used. The north-east Atlantic SST index (PCT, Principal Componennt on SST field) (Beaugrand et al. 2002c) was used as it has been recently demonstrated that this indicator highly covaries with long-term biological changes from phytoplankton to fish in the north-east Atlantic and the North Sea (Beaugrand \& Reid 2003). This index is the first principal component derived from a principal component analysis (PCA) applied on SST in the northern part of the North Atlantic Ocean (Beaugrand et al. 2002c).

Surface temperature anomalies for the Northern Hemisphere temperature (NHT) from 1958-1999 were provided by the Hadley Centre for Climate Prediction and Research, Meteorological Office, London, UK.

The winter NAO index (Hurrell 1995) for the period 1958-1999 was obtained online at www.met.rdg. ac.uk/cag/NAO/index.html. The NAO is a basin scale alternation of atmospheric mass between the Subtropical and the Arctic Atlantic (Hurrell 1995). The index used here is based on the difference of normalised sea level pressure between Lisbon, Portugal, and Stykkisholmur/Reykjavik, Iceland, since 1864 (Hurrell 1995).

The Gulf Stream and its extension the North Atlantic Current play a major role in the climate of the Northern Hemisphere (Bigg 1996). Taylor \& Stephens (1980) derived an index of the latitudinal position of the Gulf Stream North Wall (GSNW) from monthly charts measured from aircraft and satellite observations since 1966 between 79 and $65^{\circ} \mathrm{W}$ off the coast of the USA. This index is constructed by applying a PCA from the latitudinal position of the GSNW at different longitudes (Taylor \& Stephens 1980). More detailed information about the method used to calculate this index can be found in Taylor \& Stephens (1980).

Statistical analyses. Cluster analysis: The hierarchical flexible agglomerative clustering method (Lance \& Williams 1967) was applied using the original matrix $42 \mathrm{yr} \times 23$ plankton indicators to detect relatively homogeneous time periods. Lance \& Williams (1967) proposed this general model that encompasses most of the agglomerative clustering methods. By fixing the values of the 4 parameters $\alpha_{j}, \alpha_{m}, \beta, \gamma$ (see Lance \& Williams 1967, Legendre \& Legendre 1998), one can go from the single to the complete linkage. Here, $\alpha_{j}$ was fixed to $0.625, \alpha_{m}$ to $0.625, \beta$ to -0.25 and $\gamma$ to 0 so that the method was close to the unweighted centroid clustering (also called unweighted pair-group centroid method; for further details see 
Legendre \& Legendre 1998). This cluster analysis was applied to the Euclidean distance matrix $(42 \mathrm{yr} \times$ $42 \mathrm{yr}$ ) (Table 2). To minimise the effects of highfrequency (interannual) variability, a simple order-1 moving average was applied to each time series before calculating the distance matrix. This smoothing was only used for the present analysis. The resulting dendrogram was tested using the multiple response permutation procedure (MRPP; Mielke et al. 1981) using the original data (unsmoothed data). This method is a distribution-free multivariate statistical test used to compare 2 defined groups (in this case time period). The mathematics of this analysis are described in Mielke et al. (1981) and Zimmerman et al. (1985), and ecological applications as well as discussion on the robustness of the method can be found in Cornelius \& Reynolds (1991). The calculation of this test is realised into 3 steps. First, this method calculates the within-group (here period) weighted average of all pairwise distance measures (Euclidean distance) between years. Second, all years of the 2 periods tested are randomly redistributed. The number of possible permutations is equal to $\left(\mathrm{n}_{1}+\mathrm{n}_{2}\right) ! /\left(\mathrm{n}_{1} ! \times\right.$ $n_{2}$ !), where $n_{1}$ and $n_{2}$ are the number of years for the first and second period, respectively. For each permutation, the within-group weighted average of all pairwise distance measures is recalculated. Third, the probability is then assessed by dividing the number of times the simulated within-group average (calculated at Step 2) was inferior to the observed withingroup average (calculated at Step 1) by the total number of possible permutations.

Standardised principal component analysis: To identify the major long-term signal in all 23 biological time series (Table 2), a standardised PCA was performed on the correlation matrix (23 plankton indicators $\times 23$ plankton indicators). Eigenvectors were normalised as follows:

$$
U_{\mathrm{n}}=U \Lambda^{\frac{1}{2}}
$$

where $U_{\mathrm{n}}$ is the matrix of normalised eigenvectors, $U$ the matrix of eigenvectors and $\Lambda$ the diagonal matrix of eigenvalues.

Thus, the variables in the space of eigenvectors represented the linear correlation with the first and the second principal components (Legendre \& Legendre 1998). We used this mathematical property to add supplementary variables (all hydro-climatic variables), simply by calculating the linear correlation (Pearson correlation coefficient) between all hydro-climatic variables and the first 2 principal components. Thus, hydro-climatic variables had no weight in the calculation of the principal components. A similar PCA was applied to the correlation matrix (8 hydro-climatic variables $\times 8$ hydro-climatic variables).
The circle of equilibrium descriptor contribution $C$ (see Legendre \& Legendre 1998) was represented on the scatterplot of eigenvectors to see which variables contribute most strongly to the reduced space. It was calculated as:

$$
C=\sqrt{\frac{d}{p}}
$$

where $d$ is the number of dimensions and $p$ the number of variables used in the analysis. $d$ was equal to 2 in both PCAs. For the PCA performed on plankton indicators, $p=23$ and therefore $C=0.29$. For the PCA performed on hydro-climatic variables, $p=8$ and therefore $C=0.50$.

Correlation analysis: The Pearson linear correlation coefficient was used to assess the relationships between long-term changes in the ecosystem and the hydro-climatic environment. Probabilities of significance of coefficients of correlation were $\left(\mathrm{p}_{\mathrm{ACF}}\right)$ calculated, taking into consideration the temporal autocorrelation. A Box-Jenkins (1976) autocorrelation function modified by Chatfield (1996) was used to assess the temporal dependence of years. The Chelton (1984) formula was applied to adjust the degree of freedom. All methods used in the present study were programmed using MATLAB language.

\section{RESULTS}

\section{Long-term changes in the dynamic regime of North Sea marine ecosystems}

At the cut-off level of 4 Euclidean distance units, the cluster analysis (performed on long-term changes in the 23 plankton indicators for the 4 selected areas of the North Sea; Fig. 2) identified 3 periods when ecosystems were in a colder (1962-1982) and a warmer dynamic regime (1958-1960 and 1983-1999). These periods were significantly different (MRPP test, $\mathrm{p}<0.01$ ). At the cut-off level of 3, the periods 1958-1961 and 1984-1991 were significantly separated from the period 1992-1999.

A standardised PCA was performed on a table of observations (years from 1958-1999) $\times$ variables (23 biological parameters for the 4 areas of the North Sea). Fig. 3a shows the relationships between plankton indicators using the first 2 normalised eigenvectors that collectively represented $50.17 \%$ of the total variability. Hydro-climatic variables were indicated as supplementary variables. The first 2 eigenvectors showed a clear grouping between both subarctic and arctic species and separation from warm-temperate and temperate pseudo-oceanic species. Those variables, in addition to total diversity and other species assemblages in the north-eastern and central part of the North Sea, 
weighted heavily on the formation of the first principal component. Hydro-climatic variables such as SST, NHT anomalies, GSNW, NAO and to a lesser extent wind intensity and direction were linked positively to the first axis and were therefore positively related to warm-water species, whereas the relationship was negative with subarctic and arctic species. The first biological principal component (PC1B; Fig. 3b) explained 32.46\% of the

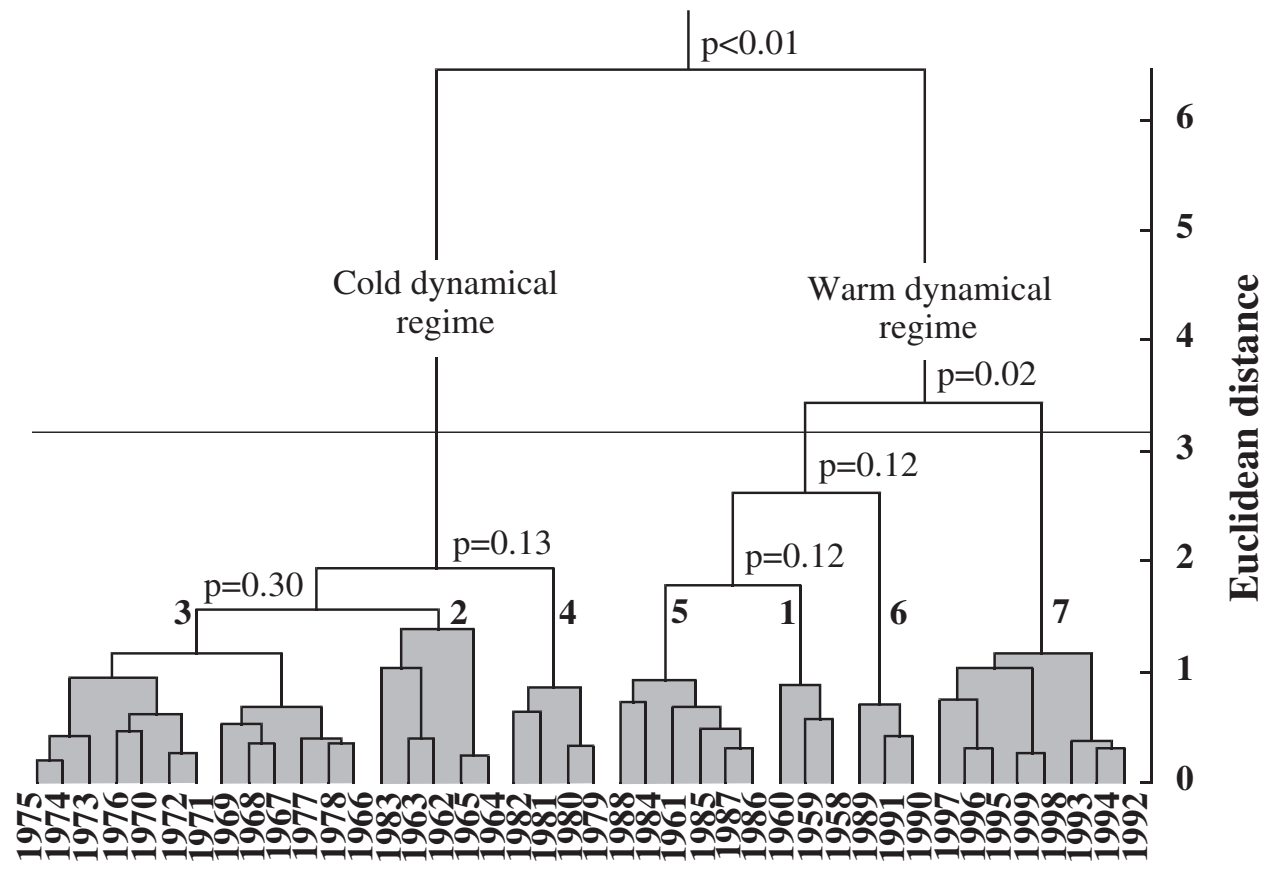

Fig. 2. Dendrogram from a cluster analysis using the Lance \& Williams (1967) hierarchical flexible algorithm, performed on a Euclidean distance matrix with all 23 species assemblage indicators for the 4 selected areas in the North Sea as variables. Probabilities from a multiple response permutation procedure test are indicated at each division of the dendrogram between the distances 4 and 1.5

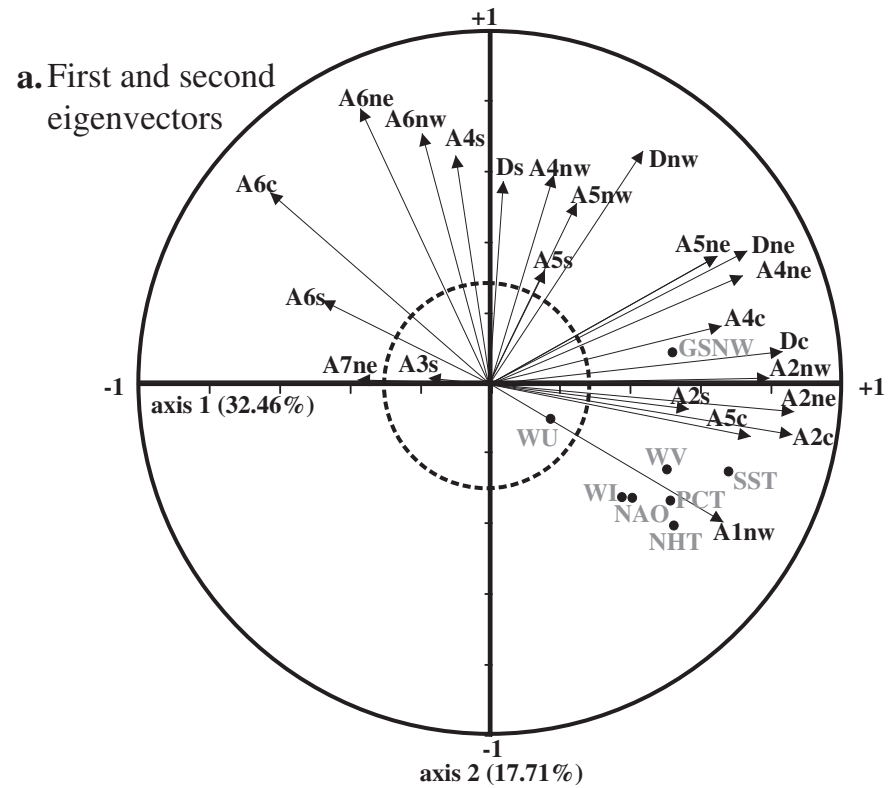

b.

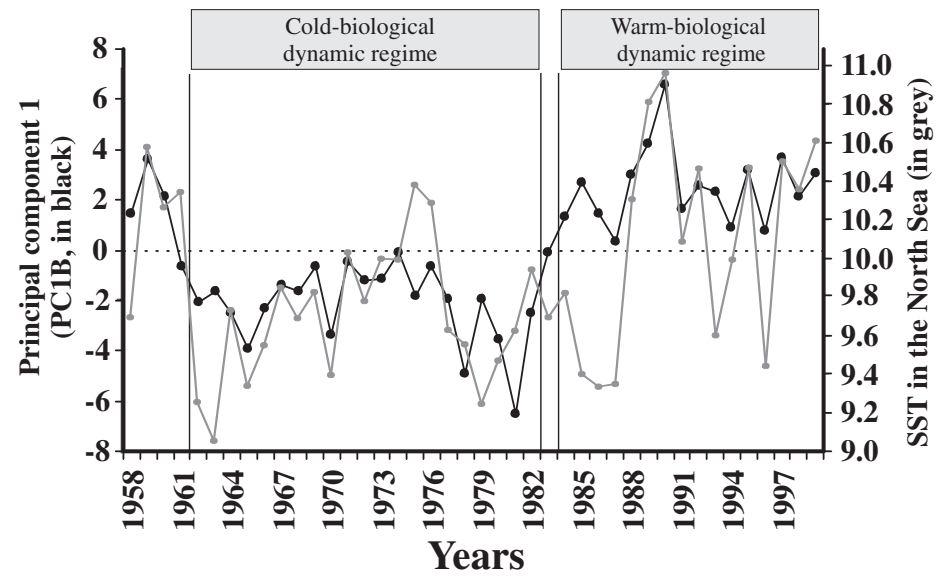

Fig. 3. Standardised principal component analysis on biological variables. (a) Normalised eigenvectors 1 and 2 (50.17\%). Circle of correlation and the circle of regime descriptor contribution $(C=0.29)$ are also displayed. Supplementary variables indicated in grey. See Table 2 for definition of the abbreviations. (b) Long-term changes in the first principal component (32.46\% of the total variance) and sea surface temperature (SST). Vertical black lines indicate the cold-biological dynamic regime and the warm-biological dynamic regime 
total variability. As 23 variables were used in the analysis, the percentage of variability explained by the principal component was far above the equiprobability $(1 / 23=4.34 \%)$. This principal component exhibited a decrease until the end of the 1970s with 2 minima: 1965 and the cold-biological episodic event (1978-1982; Edwards et al. 2002). After 1982, values of the PC showed a stepwise increase until 1985, and a maximum was reached during the warm-biological episodic event (Edwards et al. 2002), clearly detected from 1989 to 1991. After the warm anomaly, values of the PC decreased but were still high until 1999. PC1B was positively significantly related to changes in SST $\left(r_{p}=0.64\right.$, $\mathrm{p}_{\mathrm{ACF}}<0.001$; Fig. 3b). Principal components 2 to 5 (not represented), all of which were above the equiprobability value, were not correlated with any of the climatic or hydrographic variables and thus did not contribute to explaining the long-term changes in the ecosystem.

\section{Long-term changes in the hydro-climatic environment of the North Sea in relation to large-scale hydro-climatic variables}

A standardised PCA was performed on a second table with hydro-climatic variables (Table 2). Fig. 4a shows the scatterplot of the first 2 normalised eigenvectors $(61.26 \%$ of the total variability). With the exception of V-wind (westerlies), all parameters were linked positively to the first axis. SST and the NAO index were strongly related to the first axis.
Fig. 4b shows the long-term changes in the first principal component $(47.31 \%$ of the total variability), which covaried positively with PC1B. Eight variables were used in the analysis. Therefore, the percentage of variability explained by the principal component was far above the equiprobability $(1 / 8=12.25 \%)$. The second principal component $(13.95 \%$ of the total variability) did not provide any element for better understanding the nature of the changes in calanoid copepod community structure.

\section{DISCUSSION}

The CPR survey has monitored plankton ecosystems at one single depth, typically at 6 to $7 \mathrm{~m}$. Therefore, it might be dangerous to infer to the whole pelagic ecosystem. For example, changes in plankton ecosystems may have been related to a change in the depth of the seasonal pycnocline. However, calanoid copepods migrate vertically (Daro 1985) and because CPR sampling is carried out during day and night, it is unlikely that this process influenced the long-term changes in the calanoid copepods observed in this study. Other studies have also shown that the CPR survey gives a satisfactory picture of the epipelagic ecosystems (Lindley \& Williams 1980, Williams \& Lindley 1980, Batten et al. 1999).

Plankton indicators, generated by the numerical CIMOTS procedure (Beaugrand 2004), in combination with multivariate exploratory and time series analyses,
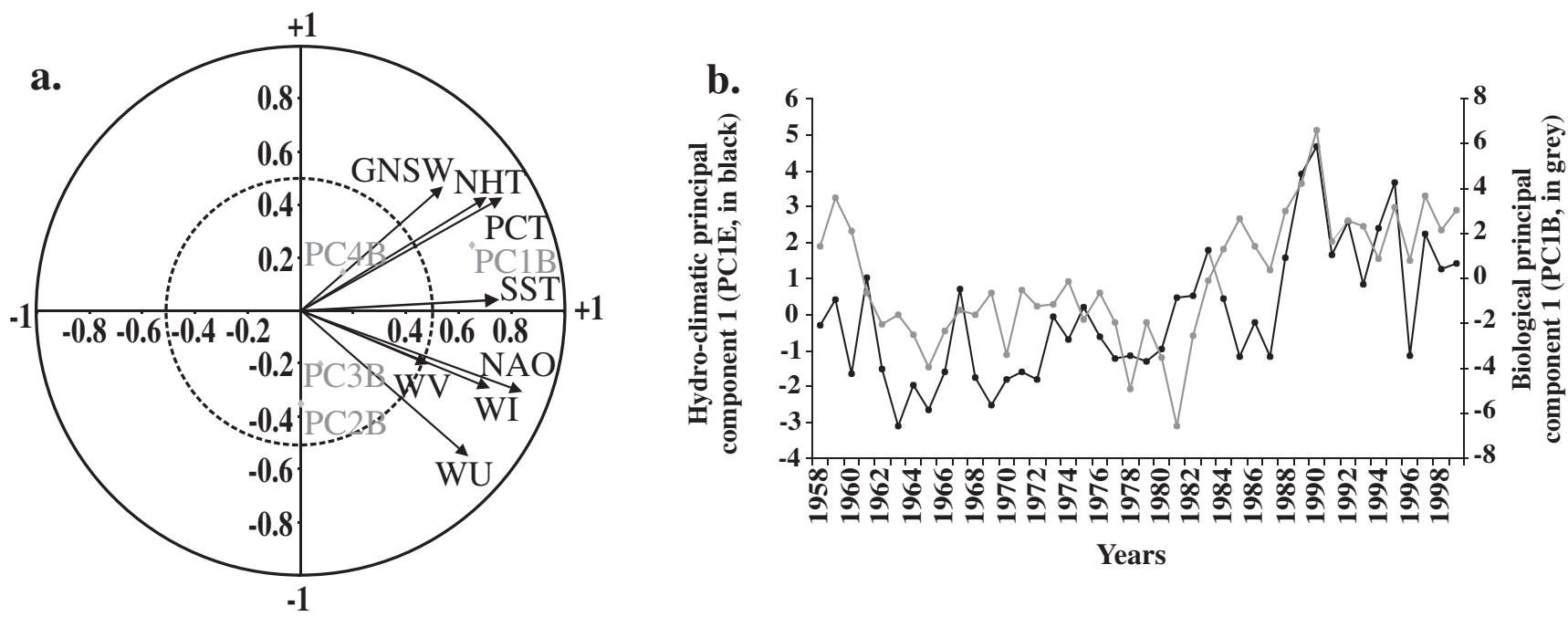

Fig. 4. Standardised principal component analysis (PCA) on hydro-climatic variables. (a) Normalised eigenvectors 1 and 2 $(61.26 \%)$. Circle of correlation and the circle of regime descriptor contribution $(C=0.50)$ are also displayed. Supplementary variables (the first 4 principal components from the PCA performed on plankton indicators) indicated in grey. (b) Long-term changes in the first principal component $(47.31 \%$ of the total variance) from the PCA performed on hydro-climatic variables (PC1E, in black) and in the first principal component from the PCA performed on ecosystem variables (PC1B, in grey). See Table 2 for definition of the abbreviations 
have allowed a better understanding of the dynamics of North Sea plankton ecosystems during the period 1958-1999. Results demonstrate the importance of using a systemic approach (Frontier \& Pichot-Viale 1993), in considering calanoid copepod community structure, to understand, explain, and possibly forecast responses of marine ecosystems to climate change. Different types of statistical analyses, mostly adapted to multivariate matrices, have been applied. The objectives were (1) to summarise the information, (2) to distinguish the major variability of both the biological and the hydro-climatic environment, (3) to detect time periods and (4) to identify relationships between biological and hydro-climatic changes. Based on the present results, a chronology of ecological events that occurred in the North Sea since 1958 can be outlined (Fig. 5).

a.

Appearance of warm-temperate species in the north-western part
of the North Sea (see Fig. 5b)

\begin{tabular}{|c|c|c|c|c|c|c|c|}
\hline \multirow[b]{2}{*}{ A2nw } & \multicolumn{4}{|c|}{$\begin{array}{l}\text { Cold-biological } \\
\text { dynamic regime }\end{array}$} & \multicolumn{3}{|c|}{$\begin{array}{l}\text { Warm-biological } \\
\text { dynamic regime }\end{array}$} \\
\hline & 0.32 & 0.37 & 0.41 & 0.29 & 0.58 & 0.71 & 0.63 \\
\hline A1nw & 0 & 0 & 0 & 0 & 0.02 & 0.04 & 0.04 \\
\hline Diversity & 2.40 & 2.30 & 2.29 & 2 & 2.78 & 2.94 & 2.47 \\
\hline Wind V $\left(\mathrm{m} \mathrm{s}^{-1}\right)$ & 0.59 & 0.51 & 0.82 & 0.91 & 0.91 & 1.51 & 1.32 \\
\hline Wind $U\left(\mathrm{~m} \mathrm{~s}^{-1}\right)$ & 1.19 & 1.23 & 1.61 & 1.47 & 1.43 & 2.44 & 1.30 \\
\hline Wind I $\left(\mathrm{m} \mathrm{s}^{-1}\right)$ & 7.28 & 7.79 & 7.93 & 8.46 & 8.43 & 8.70 & 8.48 \\
\hline $\operatorname{SST}\left({ }^{\circ} \mathbf{C}\right)$ & 9.35 & 9.67 & 10.09 & 9.65 & 9.65 & 10.63 & 10.19 \\
\hline \multirow{3}{*}{$\begin{array}{l}\text { NHT } \\
\text { NAO }\end{array}$} & -0.01 & -0.01 & -0.14 & 0.08 & 0.08 & 0.35 & 0.38 \\
\hline & -2.93 & -1.65 & 1.02 & 0.26 & 0.29 & 3.36 & 1.42 \\
\hline & CDP & CLP & WCP & CEE & $\mathbf{T P}$ & WEE & WWP \\
\hline
\end{tabular}

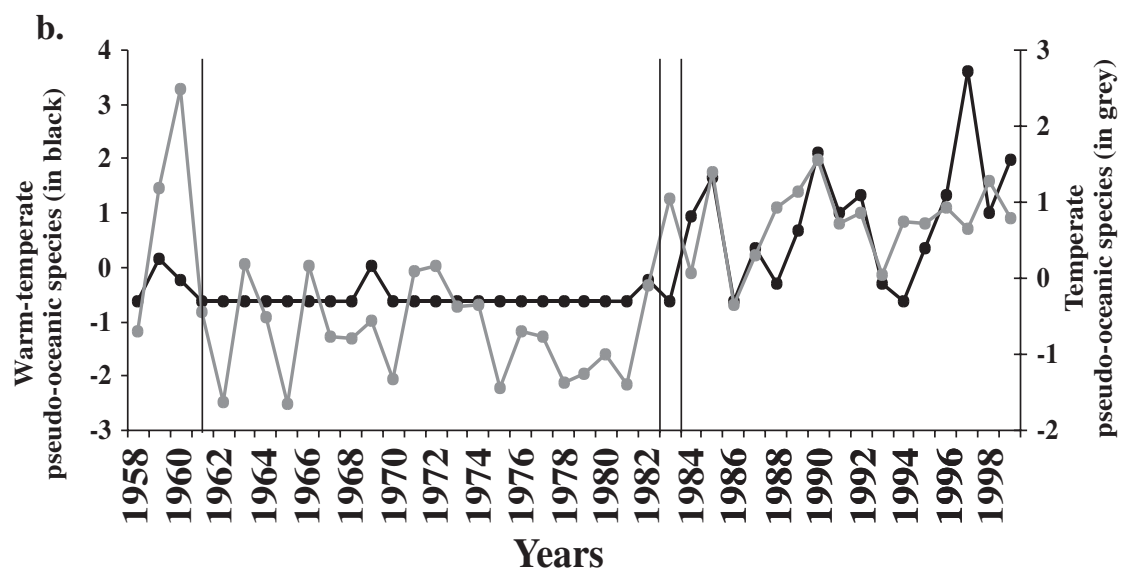

Fig. 5. (a) Chronology of events, which affected the calanoid copepod community structure and diversity in the North Sea for the period 1958-1999. Black vertical lines indicate relative boundary between the cold and warm dynamic equilibriums. Grey vertical lines identify both the cold- (CEE) and warm-biological (WEE) episodic events (Edwards et al. 2002). Dashed grey vertical lines separate different time periods; however, not significant at the threshold of 0.05 (see Fig. 2). CDP: cold-biological time period; CLP: cool-biological period; WCP: warm-biological time period; TP: transitional time period (statistically significant; see Fig. 2); WWP: warm-biological time period. The question mark for the period 1958-1960 indicates that it is not really possible to interpret the state of the ecosystem during that period because of the limited number of years. For each time period, the mean values of some important biological and hydro-climatic indices were reported. Wind V: V wind averaged for the whole North Sea (as values are positive in average; this indicates the intensity of southerlies). Wind U: U wind averaged for the whole North Sea (as values are positive in average; this indicates the intensity of westerlies). Wind I: wind intensity averaged for the whole North Sea. SST: sea surface temperature averaged for the whole North Sea. See Table 2 for definition of the other abbreviations. (b) Long-term changes in the mean number of warm-temperate (in black) and temperate (in grey) pseudo-oceanic species in the north-western part of the North Sea. Biological time periods identified in Fig. 2 in addition to the 2 biological episodic events (Edwards et al. 2002) are superimposed 
This figure shows that the switch from a cold- to a warm-biological dynamic regime was accompanied by a number of modifications in hydro-climatic forcing (e.g. wind and temperature) and by the appearance of the warm-temperate (and an increase in temperate) pseudo-oceanic species in the North Sea. While the cold-biological episodic event reported by Edwards et al. (2002) is not clearly identified by any hydro-climatic parameters, the warm-biological episodic event is clearly related to an increase in wind and temperature. Other periods, not significant at the probability level of 0.05 (see Fig. 2), are indicated in Fig. 5 and correspond to smaller changes in calanoid copepod community structure and diversity (see Fig. 3), some of which are associated with a change in hydro-climatic forcing.

\section{The cold-biological dynamic regime}

In addition to the long-term (low-frequency) variability in calanoid copepod community structure and total diversity, analyses reveal that North Sea pelagic ecosystems had 2 contrasting dynamic regimes during the period 1958-1999: a cold (1962-1982) and a warm dynamic regime (1984-1999). During the cold dynamic regime, the alternation of colder and warmer time periods may have been related to the 8 year cyclical variability of the NAO (Beaugrand \& Reid 2003).

Analyses detected the cold-biological episodic event reported by Edwards et al. (2002), which led to a pronounced reduction in calanoid copepod total diversity. Edwards et al. (2002) also noted changes in the abundance and/or composition of copepods, decapods, diatoms and dinoflagellates during that period, and Reid \& Edwards (2001) suggested that this event could have had an effect on the total biomass of North Sea fish stocks. Edwards et al. (2002) attributed these biological changes to an increased supply in water from northern currents, particularly the East Icelandic Current which carries negative anomalies of salinity (Hansen \& Kristiansen 1994). Blindheim et al. (1996) suggested that this increase in the East Icelandic Current may have strengthened the effect of the Great Salinity Anomaly (Dickson et al. 1988b) in the north-east Atlantic.

\section{The warm-biological dynamic regime}

During the warm dynamic regime (see Fig. 5a), the effects of the warm-biological episodic event on North Sea pelagic ecosystems were detected for the period 1989-1991. The warm-biological episodic event was triggered by a strong atmospheric forcing (PC1E [principal component 1 using environmental variables], high positive NAO indices, warm temperature, stronger southerlies and westerlies; see Fig. 5a). High Salinity Anomaly in the North Sea (Heath et al. 1991), increased geostrophic transport through the Rockall Trough (Reid et al. 2001a) and strong oceanic inflow were detected at the same time (Reid et al. 2001b, 2003). These may explain why many oceanic and warm-water species such as Doliolum nationalis were recorded in the North Sea (Lindley et al. 1990). Reid et al. (2003) suggested that the sustained warm-biological phase of North Sea pelagic ecosystem after the mid-1980s has been unobserved since 1900.

\section{The regime shift}

Regime shifts reflect catastrophic (as per the meaning of the catastrophe theory, e.g. Loehle 1989) changes in the dynamic regime of ecosystems (Scheffer et al. 2001). Reports of regime shifts in the marine ecosystems of the Pacific Ocean (Hare \& Mantua 2000) or the North Sea (Reid et al. 2001b) have shown that the adjustment of pelagic ecosystems to hydro-climatic fluctuations may not occur smoothly as previously thought but instead exhibit a rapid transition between 2 locally stable states. This non-linear effect has also been shown for the ocean climate system (Rahmstorf 1995, Paillard 2001) and in a myriad of terrestrial ecosystems including lakes (Scheffer et al. 2001, Scheffer \& Carpenter 2003).

The existence of a regime shift in the North Sea is still debated. Using cumulative sums (CUSUM), Taylor (2002) recently suggested that a regime shift may not have occurred in the North Sea. However, the test he used in his study was performed on abundances of just 2 species (Calanus finmarchicus and C. helgolandicus) and 1 taxonomic group (total copepods) derived from the CPR survey. Total copepod abundance cannot detect qualitative or even quantitative changes in community structure because a decrease in the abundance of one species may be compensated (partially or fully) by an increase in the abundance of another. For example in the North Sea, C. finmarchicus and C. helgolandicus have opposite long-term variability. In our study, all components of the calanoid copepod community structure were investigated (e.g. from cold- to warm-water species, oceanic to pseudo-oceanic to neritic species).

To date, the origin of the regime shift in the North Sea remains unclear. Holliday \& Reid (2001) and Reid et al. (2001a) recently provided evidence that the European Shelf Edge Current may have played an important role. Holliday \& Reid (2001) investigated the transport of oceanic water into the Rockall Trough. They found that the mean volume transport reached about $7 \mathrm{~Sv}$ in 1989 , nearly twice the usual rate $(3.7 \mathrm{~Sv})$. This event coin- 
cided with the warm-biological episodic event in the late 1980s (Edwards et al. 2002). Subsequently, Reid et al. (2001a) provided indications that strong northward advection of warm water along the European shelf edge coincided with this pulse of oceanic inflow.

This study has provided further indications about the nature of the regime shift in the North Sea. Firstly, the regime shift was clearly detected in the northern and central North Sea but not in the southern North Sea. Secondly, our study identifies the time of the regime shift for calanoid copepods to be a few years earlier (after 1983) than previously suggested (1988 according to Reid et al. 2001b). It should be noted that the timing of the regime shift may vary according to the biological
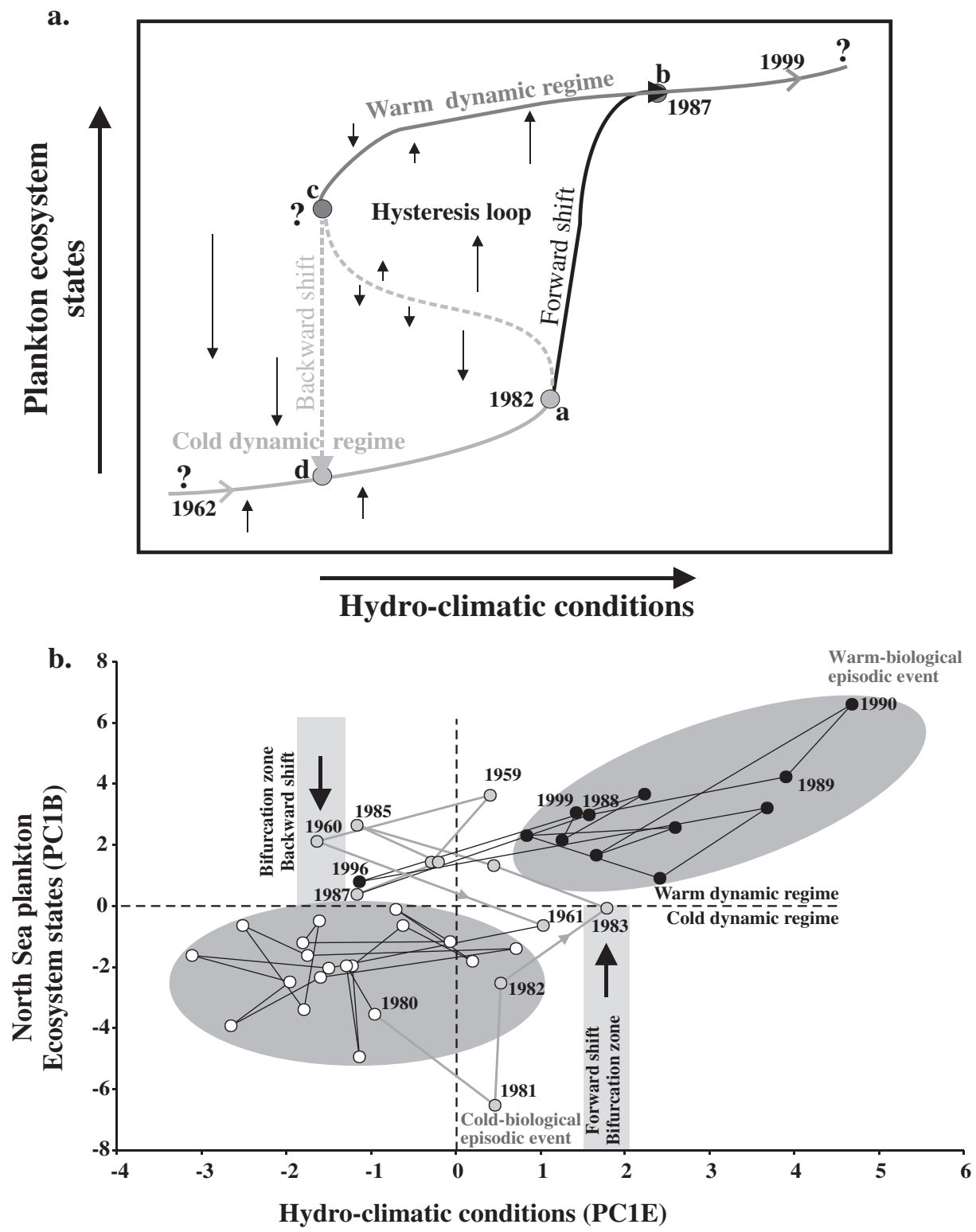

Fig. 6. (a) Hypothetical change in the dynamic regime of North Sea pelagic ecosystems before and after the regime shift. An hysteresis loop $(\mathrm{a}-\mathrm{b}-\mathrm{c}-\mathrm{d})$ is indicated although its importance is still unknown. Key events identified from the present study and other works are shown. The thick and grey dashed line indicates an unstable state. The wide black arrow (from a to b) shows the trajectory of change from the cold to the warm dynamic regime. The dashed grey line shows a trajectory that can never be observed. Other lines indicate the cold (in light grey) and warm (in dark grey) dynamic regime. The thick and grey arrow denotes the backward shift in 1960. Thin arrows show the direction of change in ecosystem state when the system is out of equilibrium. (b) Observed shift using PC1B (plankton indicators, $y$-axis) and PC1E (hydro-climatic indicators, $x$-axis). The time of both observed forward and backward shift is indicated by a black arrow. The scatterplot is divided into 4 squares. The cold-biological dynamic regime is located below the horizontal dashed line while the warm-biological dynamic regime is located above. Key years are also shown. The 2 exceptional ocean-climate anomalies (warm ocean-climate anomaly: 1989-1991; cold ocean-climate anomaly: 1978-1982) are mentioned. O: period 1960-1980; O : period 1981-1987; •: period 1988-1999; lines between the circles indicate the trajectory of the shift (in grey) and the variability around the attractor for the first (thin lines) and second (wider line) period 
and other variables used in a study as species may react differently to common hydro-climatic forcing depending upon their life history, their spatial distribution or the particular threshold values of their physiological processes (Beaugrand \& Reid 2003).

It is hypothesised that in addition to the atmospheric forcing that influenced the regime shift in the North Sea, the stepwise change in the dynamic regime of North Sea pelagic ecosystems was also triggered by a major reorganisation in the biological composition of marine ecosystems observed in the north-east Atlantic since the beginning of the 1980s (Beaugrand et al. 2002a,b). In the eastern North Atlantic Ocean and European shelf seas, strong biogeographical shifts in all copepod assemblages have occurred, with a northward extension of more than $10^{\circ}$ latitude of warmwater species associated with a decrease in the number of colder-water species. These biogeographical changes were linked positively to the warming in SST observed in the west-European basin, which in turn covaried positively with Northern Hemisphere temperature. Fig. 5b shows the appearance of both temperate (since 1982) and warm-temperate (since 1984) pseudo-oceanic species assemblage indicators in the north-western part of the North Sea. The coincidence between the appearance of these assemblages in the North Sea and the shift in the community structure in 1984 tends to suggest a link between biogeographical changes in the north-east Atlantic and the regime shift in the North Sea.

This result also suggests that the regime shift can only be understood if changes in total diversity and community structure at the scale of, at least, the northeastern North Atlantic are considered. Fig. 6a summarises the sequence of key events observed before and during the regime shift in the North Sea, in addition to hypothetical dynamic regimes and a shift trajectory. Fig. 6b shows the observed trajectory and dynamic regimes by using a scatterplot biological (PC1B; see Fig. 3b) versus hydro-climatic (PC1E; see Fig. 4b) time series. Both hypothetical and observed trajectories correspond. Fig. 6b suggests the presence of a hysteresis loop (i.e. the trajectories of the forward and the backward shift are different; see Frontier \& Pichot-Viale 1993, Rahmstorf 1995). In 1960, after a strong negative hydro-climatic forcing, the ecosystem shifted to a cold-biological dynamic regime, while from 1983, after a strong positive forcing, the system shifted towards a warmer state. It is probable that the warmbiological dynamic regime of the period 1958-1960 was related to an episodic event as the examination of other CPR-derived plankton indicators (e.g. index of phytoplankton abundance) did not show any sign of sustained warm-biological phase (Beaugrand \& Reid 2003).
There are still uncertainties about the width of the hysteresis loop (i.e. stability of the warm dynamic regime); if it is wide, many years of sustained and strong negative hydro-climatic forcing may be necessary to return to a cold dynamic regime. If the hysteresis loop is narrow, a strong perturbation or a coldepisodic event may be sufficient to trigger a backward shift. It seems that the presence of warm-temperate pseudo-oceanic species in the north-western part of the North Sea may be a good indicator of the warm dynamic regime of North Sea marine ecosystems (Beaugrand et al. 2002C; their Fig. 1). It is expected that as long as this species assemblage is detected in the north-west North Sea, ecosystems will stay in a warm dynamic regime. For both cold- and warm-biological dynamic regimes, biological systems show a lowfrequency trend, a cyclical variability and exceptional events (see Fig. 3). These latter events (especially the warm-episodic event) are informative and may provide some indications about other possible bifurcations (i.e. regime shift) if climate warming continues.

The changes observed in calanoid copepod community structure and total diversity may have strong consequences for the functioning of North Sea ecosystems, exploited resources and biogeochemical cycles. Beaugrand et al. (2003), using a plankton index indicator of the quantity and quality of plankton prey of larval cod between March and September, found that long-term changes in that plankton index explained nearly $50 \%$ of the variability in cod recruitment at Age 1. Lindley \& Batten (2002) found pronounced changes in echinoderm larvae in the north-western part of the North Sea during the 1980s. This seems to coincide with stepwise changes seen in the diversity of the macrobenthos (Warwick et al. 2002).

\section{Strong impact of temperature}

Sea temperature and temperature-based hydro-climatic indices such as PCT, NHT anomalies and GSNW were the variables the most linked to PC1B. This result indicates that temperature is a major determinant in the dynamic regime of North Sea marine ecosystems. Plankton dynamics are indeed strongly influenced by temperature (van der Spoel 1997, Lindley \& Reid 2002). Temperature may influence calanoid copepods in several ways: (1) It determines the geographical distribution of many species (Mauchline 1998). (2) It affects physiological factors such as respiration, growth, development and feeding, which in turn influences survival from the individual to the population level (e.g. Carlotti et al. 1993). Calanoid copepods may therefore be expected to show clear responses to climate warming. If the warming continues, as predicted 
by the Intergovernmental Panel on Climate Change (2001), the resilience (also called 'stability domain' by Scheffer et al. 2001) of North Sea marine ecosystems may alter and possibly lead to other regime shifts. The prediction of the future responses of North Sea pelagic ecosystems to global warming is thus highly challenging.

Acknowledgements. We thank Keith Brander (ICES, Copenhagen) for providing ICES data used in this study and for comments on the manuscript, and Scott Woodruff (NOAA/ OAR/CDC) for providing information about COADS data. We also thank Philip C. Reid, Anthony Richardson and J. Alister Lindley for comments on the research. The authors are grateful to all past and present members and supporters of the Sir Alister Hardy Foundation for Ocean Science, whose continuous efforts have allowed the long-term establishment and maintenance of the CPR dataset. The survey depends on the owners, masters and crews of the ships that tow the CPRs. This research was supported by the Department for Environment Food and Rural Affairs (DEFRA), the French programme 'Programme National en environnement côtier, thème: influence des facteurs hydroclimatiques ou anthropiques sur la variabilité spatio-temporelle des populations et écosystèmes marins' (PNEC art 4) and the French programme 'Biodiversity and Global Change' from the 'Institut Français de la Biodiversité'.

\section{LITERATURE CITED}

Batten S, Hirst AG, Hunter J, Lampitt RS (1999) Mesozooplankton biomass in the Celtic Sea: a first approach to comparing and combining CPR and LHPR data. J Mar Biol Assoc UK 79:179-181

Beaugrand G (2004) Monitoring marine pelagic ecosystems. 1: Description of a systemic approach based on plankton indicators. Mar Ecol Prog Ser 269:69-81

Beaugrand G, Reid PC (2003) Long-term changes in phytoplankton, zooplankton and salmon linked to climate. Global Change Biol 9:801-817

Beaugrand G, Ibañez F, Reid PC (2000) Long-term and seasonal fluctuations of plankton in relation to hydroclimatic features in the English Channel, Celtic Sea and Bay of Biscay. Mar Ecol Prog Ser 200:93-102

Beaugrand G, Ibañez F, Lindley JA (2001) Geographical distribution and seasonal and diel changes of the diversity of calanoid copepods in the North Atlantic and North Sea. Mar Ecol Prog Ser 219:189-203

Beaugrand G, Ibañez F, Lindley JA, Reid PC (2002a) Diversity of calanoid copepods in the North Atlantic and adjacent seas: species associations and biogeography. Mar Ecol Prog Ser 232:179-195

Beaugrand G, Reid PC, Ibañez F (2002b) Major reorganisation of North Atlantic pelagic ecosystems linked to climate change. GLOBEC Int Newsl 8:30-33

Beaugrand G, Reid PC, Ibañez F, Lindley JA, Edwards M (2002c) Reorganisation of North Atlantic marine copepod biodiversity and climate. Science 296:1692-1694

Beaugrand G, Brander K, Lindley JA, Souissi S, Reid PC (2003) Plankton effect on cod recruitment in the North Sea. Nature 426:661-664

Bigg GR (1996) The oceans and climate. Cambridge University Press, Cambridge
Blindheim J, Borovkov V, Hansen B, Malmberg SA, Turrell WR, Osterhus S (1996) Recent upper layer cooling and freshening in the Norwegian Sea. ICES-CM 1996/C:12

Box GEP, Jenkins GW (1976) Time series analysis: forecasting and control. Holden-Day, San Francisco, CA

Carlotti F, Krause M, Radach G (1993) Growth and development of Calanus finmarchicus related to the influence of temperature: experimental results and conceptual model. Limnol Oceanogr 38:1125-1134

Chatfield C (1996) The analysis of time series: an introduction. Chapman \& Hall, London

Chelton DB (1984) Commentary: short-term climatic variability in the northeast Pacific Ocean. In: Pearcy W (ed) The influence of ocean conditions on the production of salmonids in the North Pacific. Oregon State University Press, Corvallis, OR, p 87-99

Colebrook JM (1991) Continuous Plankton Records: from seasons to decades in the plankton of the North-East Atlantic. In: Kawasaki T, Tanaka S, Toba Y, Taniguchi A (eds) Long-term variability of pelagic fish population and their environments. Pergamon Press, Oxford, p 29-45

Cornelius JM, Reynolds JF (1991) On determining the statistical significance of discontinuities within ordered ecological data. Ecology 72:2057-2070

Daan N, Bromley PJ, Hislop JRG, Nielsen NA (1990) Ecology of North Sea fish. Neth J Sea Res 26:343-386

Dahl E, Danielssen DS (1992) Long-term observations of oxygen in the Skagerrak. ICES Mar Sci Symp 195:455-461

Daro MH (1985) Feeding rhythms and vertical distribution of marine copepods. Bull Mar Sci 37:487-497

Dickson RR, Kelly PM, Colebrook JM, Wooster WS, Cushing DH (1988a) North winds and production in the eastern North Atlantic. J Plankton Res 10:151-159

Dickson RR, Meincke J, Malmberg SA, Lee AJ (1988b) The 'Great Salinity Anomaly' in the northern North Atlantic, 1968-1982. Prog Oceanogr 20:103-151

Edwards M, Beaugrand G, Reid PC, Rowden AA, Jones MB (2002) Ocean climate anomalies and the ecology of the North Sea. Mar Ecol Prog Ser 239:1-10

Fransz HG, Colebrook JM, Gamble JC, Krause M (1991) The zooplankton of the North Sea. Neth J Sea Res 28:1-52

Fromentin JM, Planque B (1996) Calanus and environment in the eastern North Atlantic. II. Influence of the North Atlantic Oscillation on C. finmarchicus and C. helgolandicus. Mar Ecol Prog Ser 134:111-118

Frontier S, Pichot-Viale D (1993) Ecosystèmes. Structure, fonctionnement, évolution. Masson, Paris

Greve W (1994) The 1989 German Bight invasion of Muggiaea atlantica. ICES J Mar Sci 51:355-358

Hansen B, Kristiansen R (1994) Long-term changes in the Atlantic water flowing past the Faeroe Islands. ICES-CM 1994/S:1-16

Hare SR, Mantua NJ (2000) Empirical evidence for North Pacific regime shifts in 1977 and 1989. Prog Oceanogr 47: 103-145.

Heath MR, Henderson EW, Slesser G (1991) High salinity in the North Sea. Nature 352:116

Holliday NP, Reid PC (2001) Is there a connection between high transport of the water through the Rockall Trough and ecological changes in the North Sea? ICES J Mar Sci $58: 270-274$

Hurrell JW (1995) Decadal trends in the North Atlantic Oscillation: regional temperatures and precipitations. Science 269:676-679

Intergovernmental Panel on Climate Change (2001) Climate change 2001. The scientific basis. Cambridge University Press, Cambridge 
Kroncke I, Dippner JW, Heyen H, Zeiss B (1998) Long-term changes in macrofaunal communities off Norderney (East Frisia, Germany) in relation to climate variability. Mar Ecol Prog Ser 167:25-36

Lance GN, Williams WT (1967) A general theory of classificatory sorting strategies. I. Hierarchical systems. Comp J 9: 373-380

Legendre P, Legendre L (1998) Numerical ecology, 2nd edn. Elsevier Science BV, Amsterdam

Lindley JA, Batten SD (2002) Long-term variability in the diversity of North Sea zooplankton. J Mar Biol Assoc UK 82:31-40

Lindley JA, Reid PC (2002) Variations in the abundance of Centropages typicus and Calanus helgolandicus in the North Sea: deviations from close relationships with temperature. Mar Biol 141:153-165

Lindley JA, Williams R (1980) Plankton of the Fladen Ground during FLEX 76 II. Population dynamics and production of Thysanoessa inermis. Mar Biol 57:79-86

Lindley JA, Roskell J, Warner AJ, Halliday NC, Hunt HG, John AWG, Jonas TD (1990) Doliolids in the German Bight in 1989: evidence for exceptional inflow into the North Sea. J Mar Biol Assoc UK 70:679-682

Lindley JA, Williams R, Hunt HG (1993) Anomalous seasonal cycles of decapod crustacean larvae in the North Sea plankton in an abnormally warm year. J Exp Mar Biol Ecol $173: 47-65$

Loehle C (1989) Catastrophe theory in ecology: a critical review and an example of the butterfly catastrophe. Ecol Model 49:125-152

Mauchline J (1998) The biology of calanoid copepods. Academic Press, New York

Mielke PW, Berry KB, Brier GW (1981) Application of multiresponse permutation procedures for examining seasonal changes in monthly mean sea-level pressure patterns. Mon Weather Rev 109:120-126

Paillard D (2001) Glacial hiccups. Nature 409:147-148

Planque B, Reid PC (1998) Predicting Calanus finmarchicus abundance from a climatic signal. J Mar Biol Assoc UK 78: 1015-1018

Rahmstorf S (1995) Bifurcations of the Atlantic thermohaline circulation in response to changes in the hydrological cycle. Nature 378:145-149

Reid PC, Beaugrand G (2002) Interregional biological responses in the North Atlantic to hydrometeorological forcing. In: Sherman K, Skjoldal HR (eds) Changing states of the large marine ecosystems of the North Atlantic. Elsevier Science, Amsterdam, p 27-48

Reid PC, Edwards M (2001) Long-term changes in the pelagos, benthos and fisheries of the North Sea. Senckenb Marit 32:107-115

Reid PC, Planque B (2000) Long-term planktonic variations and the climate of the North Atlantic. In: Mills D (ed) The ocean life of Atlantic salmon. Environmental and biological factors influencing survival. Fishing News Books,

Editorial responsibility: Otto Kinne (Editor),

Oldendorf/Luhe, Germany
Bodmin, p 153-169

Reid PC, Lancelot WWC, Gieskes E, Hagmeier E, Weickart G (1990) Phytoplankton of the North Sea and its dynamics: a review. Neth J Sea Res 26:295-331

Reid PC, Edwards M, Hunt HG, Warner AJ (1998a) Phytoplankton change in the North Atlantic. Nature 391:546

Reid PC, Borges M, Svendsen E (2001a) A regime shift in the North Sea circa 1988 linked to changes in the North Sea horse mackerel fishery. Fish Res 50:163-171

Reid PC, Holliday NP, Smyth TJ (2001b) Pulses in the eastern margin current with higher temperatures and North Sea ecosystem changes. Mar Ecol Prog Ser 215:283-287

Reid PC, Edwards M, Beaugrand G, Skogen M, Stevens D (2003) Periodic changes in zooplankton of the North Sea during the twentieth century linked to oceanic inflow. Fish Oceanogr 12:260-269

Roemmich D, McGowan J (1995) Climatic warming and the decline of zooplankton in the California current. Science 267:1324-1326

Scheffer M, Carpenter S (2003) Catastrophic regime shifts in ecosystems: linking theory to observation. Trends Ecol Evol 18:648-656

Scheffer M, Carpenter S, Foley JA, Folke C, Walker B (2001) Catastrophic shifts in ecosystems. Nature 413:591-596

Stephens JA, Jordan MB, Proctor R (1998) The effects of fluctuations in the North Sea flows on zooplankton abundance. J Plankton Res 20:943-956

Taylor AH (2002) North Atlantic climatic signals and the plankton of the European continental shelf. In: Sherman $\mathrm{K}$, Skjoldal HR (eds) Changing states of the large marine ecosystems of the North Atlantic. Elsevier Science, Amsterdam, p 3-26

Taylor AH, Stephens JA (1980) Latitudinal displacements of the Gulf Stream (1966-1977) and their relation to changes in temperature and zooplankton abundance in the NE Atlantic. Oceanol Acta 3:145-149

van der Spoel S (1997) Pelagic biogeography and temperature. Ann Inst Océanogr 73:185-194

Warner AJ, Hays GC (1994) Sampling by the continuous plankton recorder survey. Prog Oceanogr 34:237-256

Warwick RM, Ashman CM, Brown AR, Clarke KR and 6 others (2002) Inter-annual changes in the biodiversity and community structure of the macrobenthos in Tees Bay and the Tees estuary, UK, associated with local and regional environmental events. Mar Ecol Prog Ser 234: $1-13$

Williams R, Lindley JA (1980) Plankton of the Fladen Ground during FLEX 76 I. Spring development of the plankton community. Mar Biol 57:73-78

Woodruff S, Slutz R, Jenne R, Steurer P (1987) A comprehensive ocean-atmosphere dataset. Bull Am Meteorol Soc 68: $1239-1250$

Zimmerman GM, Goetz HP, Mielke W (1985) Use of an improved statistical method for group comparisons to study effects of prairie fire. Ecology 66:606-611

Submitted: October 30, 2003; Accepted: April 27, 2004

Proofs received from author(s): December 14, 2004 